\title{
Multidisciplinary approach to orbital decompression. A review
}

\author{
L'approccio multidisciplinare alla decompressione orbitaria. Una review \\ Claudio Parrilla², Dario Antonio Mele¹, Silvia Gelli², Lorenzo Zelano², Francesco Bussu³, Mario Rigante², \\ Gustavo Savino ${ }^{4}$, Emanuele Scarano ${ }^{5}$ \\ ${ }_{1}^{1}$ Otorhinolaryngology and Head-Neck Surgery Unit, "A. Gemelli" Hospital Foundation IRCCS, Catholic University of the Sacred \\ Heart, Rome, Italy; ${ }^{2}$ Endocrinology Unit, "A. Gemelli" Hospital Foundation IRCCS, Catholic University of the Sacred Heart, Rome, \\ Italy; ${ }^{3}$ Division of Otolaryngology, Università di Sassari, Italy; ${ }^{4}$ Ophthalmology Unit, "A. Gemelli" Hospital Foundation IRCCS, \\ Catholic University of the Sacred Heart, Rome, Italy; ${ }^{5}$ Division of Otolaryngology, Azienda Ospedaliera Pia Fondazione di Culto e \\ Religione Cardinale G. Panico, Tricase, Italy
}

\begin{abstract}
SUMMARY
Endoscopic orbital surgery has become a highly evolving multidisciplinary surgical field thanks to development in technical skills of ophthalmologists and otolaryngologists. These advances expanded the clinical application of orbital decompression, with a growing body of literature describing the multidisciplinary management of thyroid eye disease and compressive optic neuropathy, since 1990. Although techniques have improved considerably, only few Randomized Control Trials (RCT) provide evidence to support recommendations in clinical practice. This review provides an overview of the current knowledge of orbital decompression to clarify which is the most standardized therapeutic strategy. In the literature, we observed several approaches with contradicting results and the comparison of different surgical techniques was biased by inclusion of patients at different stage of disease (active or inactive), different surgical indications (dysthyroid neuropathy or disfiguring proptosis) and measures of outcomes (such as different system for ocular motility evaluation). The timing of surgical decompression is one of the debated issues. One RCT focusing on Graves' orbitopathy showed how intravenous corticosteroids achieve better visual recovery than surgical orbital decompression; but in case of absent or poor response to medical therapy the patient should undergo surgery within two weeks. There is slight evidence that the removal of the medial and lateral wall (so-called balanced decompression) with or without fat removal could be the most effective surgical technique, with low complication rate, but an increasing number of authors are promoting, for selected cases, a pure endoscopic surgical approach (with removal of medial and infero-medial orbital wall), less invasive than the balanced one; the latter indicated to more severe proptosis or diplopia after endoscopic procedure. Three-wall decompression is chosen for high degrees of proptosis, but complications are more frequent. Timing of surgical orbital decompression, in particular when a concomitant optic neuropathy is present, is still to be determined. Additional ophthalmological procedures are needed to restore normal eye function and cosmesis. Strabismus surgery to address diplopia and lowering the position of the upper eyelid represent some of the additional steps for the final rehabilitation of Graves' orbitopathy. The main clinical outcomes including visual acuity, proptosis, and new-onset diplopia are changing. Recent studies focused on the development of imaging measurements in order to objectively evaluate the surgical results and QOL questionnaires are gaining increasing importance.
\end{abstract}

KEY WORDS: nasal endoscopy, orbital decompression, thyroid eye disease, compressive optic neuropathy

\section{RIASSUNTO}

La chirurgia endoscopica orbitaria rappresenta un ambito multidisciplinare in costante evoluzione grazie allo sviluppo delle tecniche sia in ambito oftalmologico che otorinolaringoiatrico. Tali progressi hanno esteso le applicazioni cliniche della decompressione orbitaria, con incremento del numero di lavori in letteratura, volti a descrivere la gestione multidisciplinare dell'orbitopatia tiroidea e della neuropatia ottica compressiva, a partire
Received: October 27, 2020

Accepted: January 15, 2021

\section{Correspondence}

Dario Antonio Mele

Otorhinolaryngology, Head and Neck Surgery,

"A. Gemelli" Hospital Foundation IRCCS, Catholic University of the Sacred Heart largo A. Gemelli 8, 00168 Rome, Italy

E-mail: darioam90@gmail.com

Funding

None.

Conflict of interest

The Authors declare no conflict of interest.

How to cite this article: Parrilla C, Mele DA, Gelli S, et al. Multidisciplinary approach to orbital decompression. A review. Acta Otorhinolaryngol Ital 2021;41(SUPPL.1):S90-S101. https://doi.org/10.14639/0392-100X-suppl.1-41-2021-09

() Società Italiana di Otorinolaringoiatria e Chirurgia Cervico-Facciale

\section{(c) (1) $(9)$}

This is an open access article distributed in accordance with the CC-BY-NC-ND (Creative Commons Attribution-NonCommercial-NoDerivatives 4.0 International) license. The article can be used by giving appropriate credit and mentioning the license, but only for non-commercial purposes and only in the original version. For further information: https:// creativecommons.org/licenses/by-nc-nd/4.0/deed.en 
dagli anni '90. Sebbene le tecniche si siano evolute notevolmente, solo pochi studi controllati randomizzati mostrano evidenze a supporto di indicazioni per la pratica clinica. Questa review fornisce una panoramica delle conoscenze attuali sulla decompressione orbitaria, per chiarire quali siano le strategie terapeutiche maggiormente standardizzate. In letteratura, abbiamo osservato i diversi approcci con risultati contrastanti e il confronto delle varie tecniche chirurgiche è influenzato dall'inclusione di pazienti in stadio di malattia differente (fase attiva o inattiva), da differenti indicazioni alla chirurgia (neuropatia distiroidea o proptosi sfigurante) e metodi di misurazione dei risultati (come ad esempio vari sistemi per la valutazione della motilità oculare). La tempistica della decompressione chirurgica è un altro dei temi ancora oggi dibattuti. Uno studio clinico randomizzato ha mostrato come la terapia steroidea endovenosa consenta un miglior recupero visivo rispetto alla decompressione orbitaria chirurgica; ma in caso di scarsa risposta alla terapia medica il paziente dovrebbe essere sottoposto a chirurgia entro due settimane. C'è una lieve evidenza che la rimozione delle pareti mediale e laterale (cosiddetta decompressione bilanciata) con o senza rimozione del grasso orbitario rappresenti la tecnica chirurgica più efficace, con un basso tasso di complicanze. La decompressione a tre pareti è scelta in caso di proptosi di alto grado, ma le complicanze sono più frequenti. Un numero crescente di autori sta promuovendo, per casi selezionati, un approccio chirurgico puramente endoscopico (con rimozione della parete orbitaria mediale e infero-mediale), meno invasivo della decompressione bilanciata; quest'ultima appare indicata nei casi di proptosi più grave o di diplopia post-procedura endoscopica. La corretta tempistica della decompressione orbitaria è ancora da determinare, soprattutto se presente una concomitante neuropatia ottica. Procedure aggiuntive oftalmologiche sono necessarie per la normale funzionalità e cosmesi. La chirurgia dello strabismo per correggere la diplopia e l'abbassamento della posizione della palpebra superiore rappresentano alcuni dei passaggi successivi per la riabilitazione finale dell'orbitopatia di Graves. I principali outcome attualmente valutati includono acuità visiva, proptosi e diplopia di nuova insorgenza. Studi recenti si focalizzano sullo sviluppo di misurazioni sull'imaging per valutare i risultati chirurgici e i questionari sulla qualità della vita stanno acquisendo importanza sempre maggiore.

PAROLE CHIAVE: endoscopia nasosinusale, decompressione orbitaria, orbitopatia di Graves, neuropatia ottica compressiva

\section{Introduction}

Orbital decompression may be indicated for patients with orbital abscess, periorbital or orbital hematoma, neoplasm, cosmesis in patients with proptosis for other reasons, but the most common indication for orbital decompression is represented by Thyroid Eye Disease (TED), also called Graves' Orbitopathy (GO).

Unfortunately reaching the cure of GO, defined as both restoration of normal quality of life and complete regression of aesthetic and functional ocular impairment, is a rare occurrence in real-life patients, treated with medical therapy. Although the effort of preventive, immunosuppressive and novel targeted treatment, considering the complex pathogenesis and natural history of GO, the rate of patients that need ocular surgery is still elevated, making surgery a valid and often necessary therapeutic option in the multidisciplinary management of $\mathrm{GO}^{1}$.

In 1990 Kennedy et al. introduced the transnasal endoscopic approach for orbital decompression.

Since then, endoscopic orbital surgery has become a highly evolving multidisciplinary surgical field thanks to development in technical skills and cooperation of ophthalmologists and otolaryngologists ${ }^{2}$.

These advances expanded the clinical applications of endoscopic transnasal orbital decompression technique in the management of TED and compressive optic neuropathy $(\mathrm{CON})$, leading to a growing body of literature in the otolaryngology and ophthalmology communities. In his first study, Kennedy reported a mean improvement of $4.7 \mathrm{~mm}$ in Hertel exophtalmometry measurement after inferiormedial wall decompression with transnasal endoscopic technique ${ }^{2}$. However, several early reports of endoscopic decompression described new-onset diplopia in up to $45 \%$ of cases ${ }^{3}$. The consequent technical refinement was represented by the preservation of an inferior-medial orbital bone strut in endoscopic orbital decompression that resulted in a considerable reduction in this complication ${ }^{4}$. This technical evolution was the result of a multidisciplinary team-work, as described by Goldberg, Shorr and Cohen in $1992^{5}$. In fact, the expertise of otolaryngologist and ophthalmologist permitted to understand the importance of the orbital strut and suspensory ligament complex to preserve globe position after endoscopic surgery. The subsequent step has been represented by the preservation of a medial periorbital strip to reduce the medial rectus muscle prolapse into nasal cavity ${ }^{6}$.

What the ophthalmologists earned from endoscopic approach, for example, was the improvement in visualization of the posterior medial wall, limiting the risk of optic nerve injury and maximizing the extent of decompression at the orbital apex: this is of paramount importance in case of rapidly progressive thyroid disease-related optic neuropathy. What the otolaryngologist learned from the oculoplastic surgeon was the direct visualization of the infra-orbital nerve that permits extensive (both medial and lateral to the nerve) inferior wall decompression in case of external transconjunctival and lateral canthal approach. This approach enables simultaneous three-wall decompression also, addressing a balancing effect because both the inferior-medial and lateral wall are decompressed, reducing the incidence of new-onset postoperative diplopia. 


\section{Thyroid Eye Disease}

Orbital involvement in Graves' disease has a complex pathophysiology, resulting from the deposition of immune complexes that cause oedema and fibrosis of the extraocular muscles and orbital fat. The retro-orbital pressure increases and causes proptosis and exophthalmos, threatening the vision due to vascular impairment or stretching of the optic nerve.

GO, which is the main extra-thyroidal manifestation of Graves' disease, is a rare pathology and still represents a clinical and therapeutic challenge ${ }^{7}$.

Although the role of TSH receptor activating autoantibodies (TSHRAb) on orbital adipogenesis has been widely demonstrated in literature, the complex pathogenesis of GO is not clear yet. A new promising pathogenetic mechanism has been recently discovered, based on an active "crosstalk" between TSH-R and IGF-1R in thyrocytes and orbital fibroblast, which lead to activation of an IGF-1R-dependent downstream intracellular pathway. Although GO is present in about $25 \%$ of Graves' Disease cases, fortunately, the sight-threatening variant is a rare occurrence ${ }^{8}$.

\section{Therapeutic management of TED}

According to the recent Guidelines, the therapy of GO has to be gauged on two main parameters, Severity and Activity, which can be evaluated through validated scores, such as NOSPECS and Clinical Activity Score (CAS) ${ }^{9}$. The EUGOGO classification defines disease severity as sightthreatening, moderate-to-severe, and mild Graves' Orbitopathy ${ }^{10}$ (Tab. I).

In case of mild GO, an oral daily dose of $200 \mathrm{mcg}$ of Selenium appears to be effective as maintenance therapy, although its role in preventing orbitopathy has still to be clarified ${ }^{11}$. Furthermore, local measures, such as teardrops, ointments or gel, appear to be useful, particularly in alleviating ocular dryness or foreign body sensation. If diplopia impacts on the quality of life, using corrective prisms may be a valid option. Botulin injection has been tested too, with apparently transient benefits in reducing eyelid retraction ${ }^{12}$.

Intravenous high-dose glucocorticoids represent the thera- peutic cornerstone of Active GO. Indeed, in moderate-to-severe active $\mathrm{GO}$, the first line approach consists in intravenous methylprednisolone, administrated weekly at initial dose of $0.5 \mathrm{~g}$ for 6 weeks, then 0.25 for other 6 weeks $(4.5 \mathrm{~g} \mathrm{cu}$ mulative dose). This therapeutic scheme appears to have higher efficacy and fewer adverse effect then glucocorticoids oral administration. The optimal cumulative dose appears to be 4.5-5 g of methylprednisolone, but higher doses (up to $8 \mathrm{~g}$ ) can be used for more severe forms ${ }^{13}$. Patients with sight-threatening GO, due to Dysthyroid Optic Neuropathy (DON) or severe corneal exposure, should be rapidly treated with high doses of intravenous glucocorticoids as firstline treatment. A commonly used regimen consists of giving $1 \mathrm{~g}$ of intravenous methylprednisolone for three consecutive days, that can be repeated on the subsequent week. It is important to strictly control clinical conditions because in case of absent or poor response, the patient should undergo orbital decompression within two weeks ${ }^{9}$ (Fig. 1, Tab. II).

However, to achieve the reduction of relapse rates and the optimization of the final results, it seems necessary to resort to combinations of other current therapies, as the active disease could last 1-2 years and often a relapse occurs upon withdrawal of glucocorticoids ${ }^{14}$.

\section{Radiotherapy}

Orbital radiotherapy, usually with a cumulative dose of 10 to 20 Gy per orbit, can be used as second-line therapy, when GO results to be still active after glucocorticoids treatment, particularly in case of diplopia and motility disorders. In randomized clinical trials, radiotherapy appeared to be as effective as oral glucocorticoid therapy and may have a synergic effect if combined with intravenous steroids. Although data on safety seem to be reassuring, further studies are needed to assess the real long-term effectiveness and safety, because of controversial for the theoretical concerns about carcinogenesis, especially for younger patients, and other side effects such as retinopathy and cataract ${ }^{15-17}$.

Antiproliferative agents

Mycophenolate mofetil (MMF) inhibits the proliferative

Table I. Severity classification in Graves' Orbitopathy, recommendations and levels of evidence (from EUGOGO ${ }^{10}$ ).

\begin{tabular}{|c|c|c|}
\hline Classification & Recommendation & $\begin{array}{l}\text { Level of } \\
\text { evidence }\end{array}$ \\
\hline Sight-threatening GO: DON and/or corneal breakdown & Immediate intervention & IV, C \\
\hline $\begin{array}{l}\text { Moderate-to-severe G0: eye disease with sufficient impact on daily life (lid retraction } \geq 2 \\
\text { mm, exophthalmos } \geq 3 \mathrm{~mm} \text {, moderate or severe soft tissue involvement) }\end{array}$ & $\begin{array}{l}\text { Active: immunosuppression } \\
\text { Inactive: surgical intervention }\end{array}$ & IV, C \\
\hline $\begin{array}{l}\text { Mild GO: minor impact on daily life (minor lid retraction }<2 \mathrm{~mm} \text {, exophthalmos }<3 \mathrm{~mm} \text {, mild } \\
\text { soft tissue involvement, transient or no diplopia, corneal exposure responsive to lubricants) }\end{array}$ & Local measures to alleviate symptoms & IV, C \\
\hline
\end{tabular}

DON: Dysthyroid Optic Neuropathy; GO: Graves' Orbitopathy. 

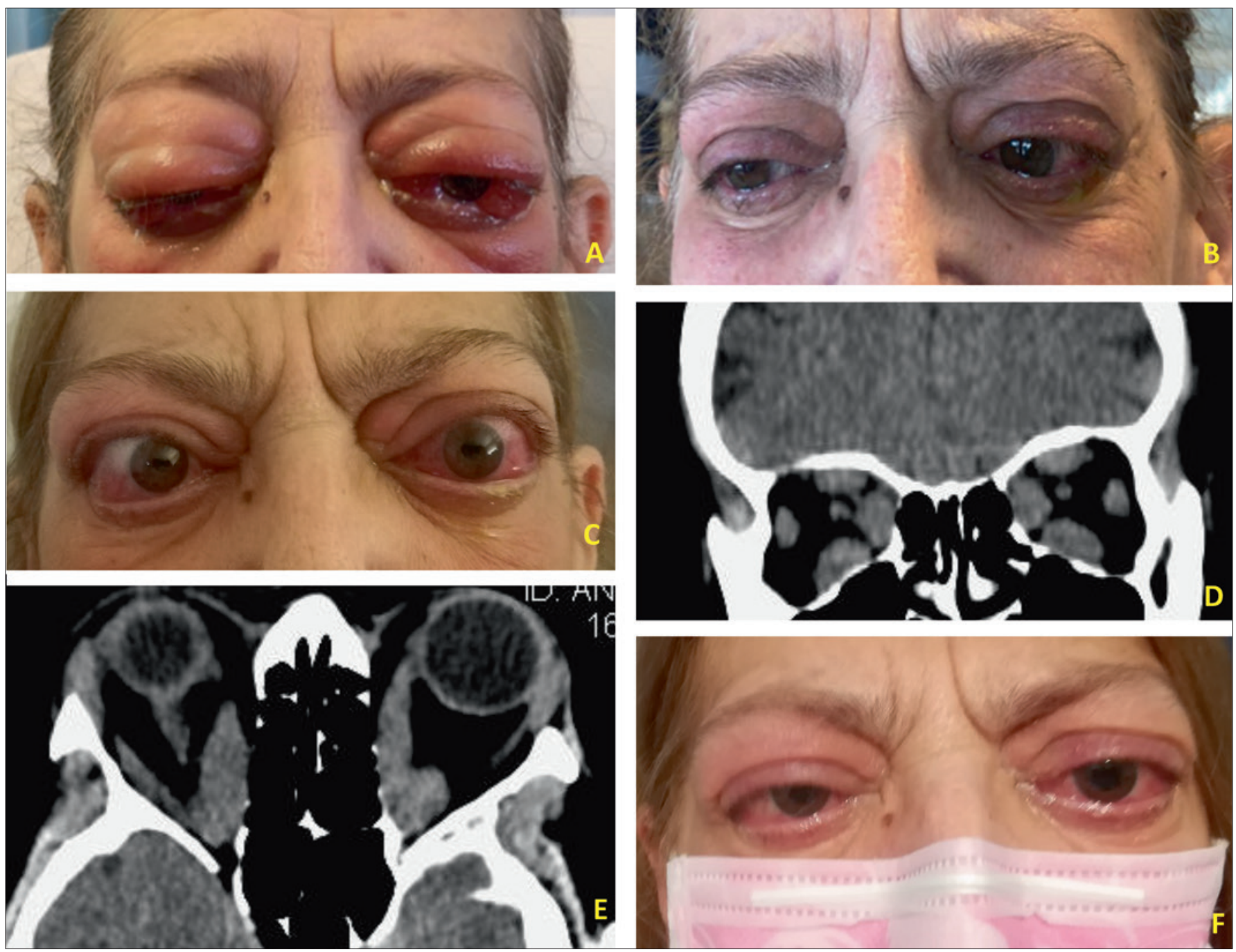

Figure 1. 63-year-old female patient, smoker, affected by active, sight-threatening G0, treated with administration of $1 \mathrm{~g}$ of intravenous methylprednisolone for three consecutive days. (A) Patient before therapy. (B) Two weeks after therapy. After thyroidectomy, a better control of hormonal levels was achieved. (C) Two months later, her visual acuity worsts to right eye: 4/20 left eye: 3/20 with anomalous colour vision test (dysthyroid optic neuropathy). (D-E) On CT-scans images, all the EOMs are enlarged with apex crowding. (F) After endoscopic bilateral endonasal optic nerve and medial wall decompression the visual acuity has greatly improved, and a $4 \mathrm{~mm}$ of proptosis reduction.

CT: computed tomography; EOMs: Extraocular muscles; GO: Graves' Orbitopathy.

responses of $\mathrm{T}$ and $\mathrm{B}$ lymphocytes and has a mechanism of a direct effect on orbital fibroblasts ${ }^{18}$; Cyclosporin, inhibits calcineurin pathway reducing IL-2, that is highly produced by T-cells activated in GO. Both MMF and Cyclosporin showed benefit in ocular symptoms and quality of life ${ }^{19}$. Methotrexate and Azathioprine have also been evaluated for utility in GO management as steroid-sparring agents, but more data are needed ${ }^{20}$.

\section{Targeted therapy}

Several monoclonal antibodies have been tested as novel therapeutic options in second-line treatment for Active GO.
Tocilizumab, a humanized monoclonal antibody directed against the IL-6 receptor, showed efficacy in terms of activity reduction ${ }^{21}$. A multicentre, randomized, trial versus placebo, showed that the use of tocilizumab in glucocorticoid-resistant GO showed a reduction in Clinical Activity Score (CAS) of at least 2 points, improvement in EUGOGO ophthalmic score and a bigger reduction of exophthalmos ${ }^{22}$. Most adverse effects tend to be mild and transient; however, a consistent risk of developing opportunistic infections has been noted during treatment for rheumatoid arthritis and need to be monitored ${ }^{23}$. Rituximab is a chimeric mouse-human monoclonal antibody, which targets the 
Table II. Glucocorticoids and orbital decompression in Dysthyroid Optic Neuropathy (from EUGOGO ${ }^{10}$ ).

$\begin{array}{ll}\text { Management of DON } & \text { Level of evidence } \\ \text { GCs and surgical decompression are effective in patients with DON } & \text { III, B } \\ \text { High-dose i.v. GCs is the preferred first-line treatment for DON } & \text { III, B } \\ \text { If the response to GCs is absent after 1-2 weeks, prompt orbital decompression should be carried out } & \text { IV, C } \\ \text { Orbital decompression should be performed promptly in case of DON 0 corneal breakdown in patients who cannot tolerate GCs } & \text { III, B }\end{array}$

DON: Dysthyroid Optic Neuropathy; GCs: Glucocorticoids; i.v.: intravenous.

B-lymphocyte antigen CD20. Two clinical trials reported contradictory outcomes: no benefit in one trial, when compared with placebo; a significant improvement in CAS, when compared with intravenous steroids, in the other ${ }^{24,25}$.

Indications for surgery

Generally speaking, it is recommended to avoid surgery in Active TED, because it is evident that surgical procedures during this phase may increase orbital inflammation ${ }^{26}$.

Urgent indications: surgical indication for orbital decompression can be considered in patients with active GO who are nonresponsive or intolerant to glucocorticoids, if waiting for spontaneous inactivation could be a risk for vision loss ${ }^{27}$, in case of CON (estimated incidence 3-9\% of TED patients) ${ }^{28}$. In fact, extraocular muscle enlargement could restrict the vascular supply to the optic nerve: this is the most well-accepted mechanism of DON. The diagnosis of DON remains still challenging and controversial, and possible clinical findings are represented by decreased visual acuity, a relative afferent pupillary defect, altered colour vision, optic disc abnormalities and visual field defects. In this case, the amount of orbital wall removal is particularly critical and should be achieved as complete as possible along the intraorbital portion of the optical nerve ${ }^{29}$.

Extreme eye proptosis can also determine vision loss: persistent eyelid retraction caused by persistent inflammation and scarring of the eyelid retractors increasing corneal exposure, predisposing patients to ulceration and subsequent vision compromise.

Nonurgent indications: orbital decompression for disfigur-
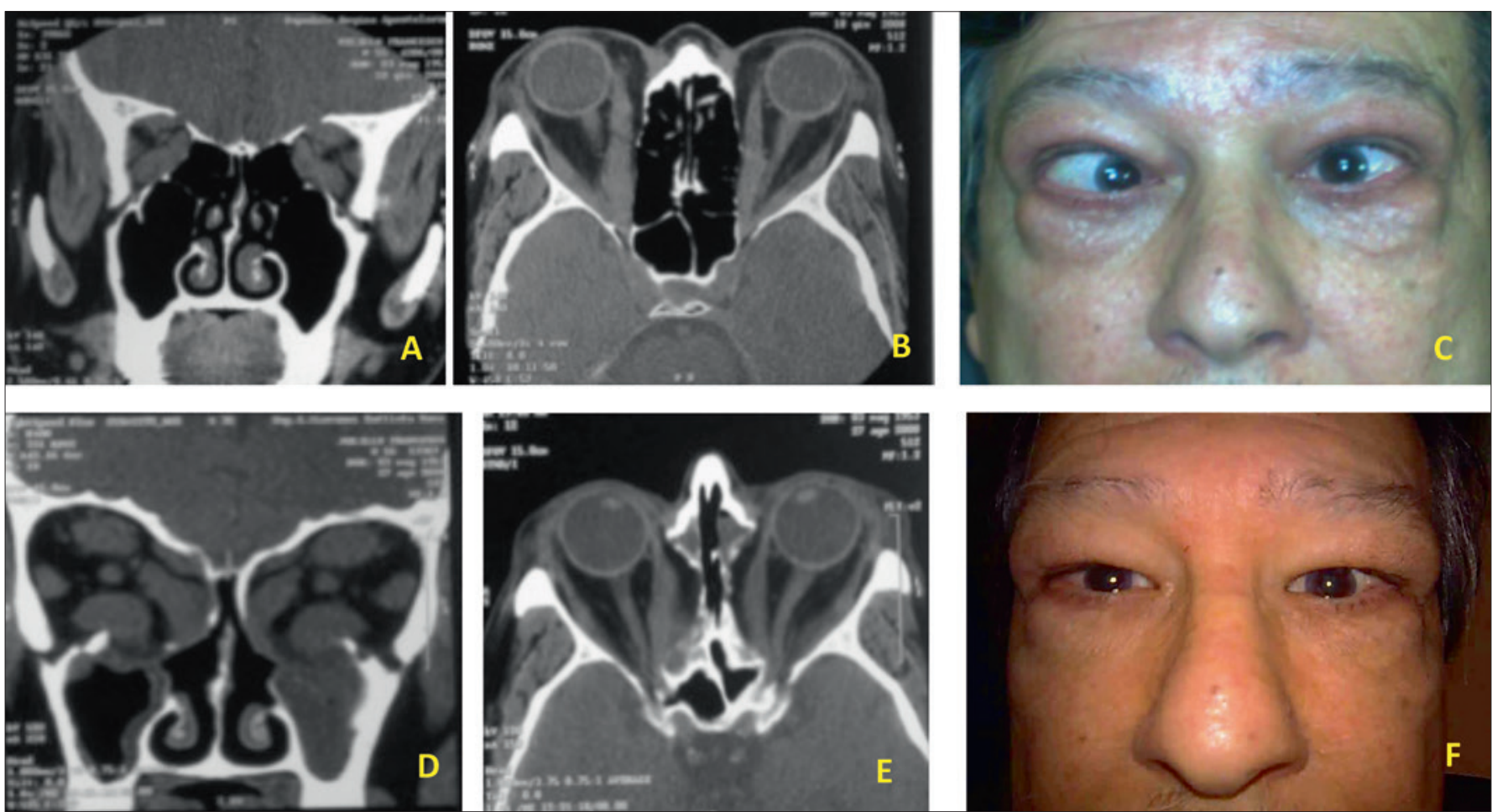

Figure 2. 65-years old, male patient affected by severe TED with proptosis and strabismus. (A-C) Pre-operative CT-scan images and appearance. (D-F) CT-scan images and appearance after bilateral endoscopic orbital decompression.

CT: computed tomography; TED: Thyroid Eye Disease. 
Table III. Timing and the order for surgery in Graves' Orbitopathy (from EUGOGO ${ }^{10}$ ).

Timing and the order for surgery

Surgical management should proceed in the sequence: orbital decompression, squint surgery, lid lengthening with blepharoplasty

Rehabilitative surgery should be performed in patients with inactive GO for at least 6 months

GO: Graves' Orbitopathy.

\section{Level of evidence}

III, B

III, B ing exophthalmos could be deferred until the orbitopathy has been inactive for at least 6 months ${ }^{27}$. Other nonurgent indications are represented by chronic retrobulbar pain or discomfort, congestion, ocular hypertension and diplopia (Fig. 2).

The majority of patients presents a good response to conservative treatments, only in 5\% of cases an orbital decompression surgery is demanded in the $1^{\text {st }}$ year after diagnosis, but in the ten years after diagnosis this rate rise up to $20 \%{ }^{28}$. In relation to the staging of the surgical ophthalmic procedures for the rehabilitation of the patients affected by the TED, the decompression should be the first procedure performed, as it can affect ocular motility ${ }^{30}$. This is followed by eyelid surgery, which can be affected by both decompression and strabismus surgery ${ }^{31}$. Some have challenged this paradigm, suggesting that there is minimal change in upper eyelid position with decompression or strabismus surgery and that simultaneous upper eyelid and decompression surgery may be performed in order to shorten rehabilitation intervals ${ }^{32}$ (Tab. III).

There are no absolute surgical contraindications to orbital decompression surgery; patients under anticoagulant treatment should discontinue the assumption preoperatively because of the major risk of bleeding intraoperatively that could impact negatively on surgery and the risk of postoperative haemorrhage. When a concomitant paranasal sinuses disease is present (sphenoidal and/or frontal rhinosinusitis), a parallel surgical opening of the involved sinuses could be addressed even if not needed for decompression surgery. Most of the studies show the efficacy and relative safety of orbital decompression ${ }^{33}$; however, the available studies do not allow any meaningful comparison of the available approaches ${ }^{27}$. Orbital decompression can be achieved with different surgical techniques: fat decompression, orbital floor or medial or inferior-medial wall decompression, orbital lateral wall decompression isolated or associated with the other wall decompression ${ }^{31}$.

\section{Multidisciplinary surgical approaches in orbital decompression}

\section{Transantral}

Before the endoscopic era, the Walsh-Ogura transantral approach was the gold standard for treatment of exophthalmos in patients with Graves'disease ${ }^{34}$.
This approach started with a sublabial incision in the oral vestibule mucosa, taking care to not injure the infraorbital nerve during the exposition of the anterior wall of the maxillary sinus. Then an osteoplastic anterior maxillotomy is performed, by the temporary removal of a bony gusset that is replaced with microplates at the end of the procedure. The orbital floor and the lamina papyracea are then exposed and resected, resulting in orbital decompression and subsequent immediate reduction in proptosis.

It is important to preserve a bony bridge together with the infra-orbital canal, avoiding downward displacement of the eyeball and subsequent diplopia.

\section{Complications}

- hypoesthesia of the cheek, the lateral nasal ala, and the anterior teeth, due to lesion or temporary stretching of infra-orbital nerve in the bony canal inside the orbital floor or after its exit from the infraorbital foramen;

- paresis of extraocular muscles (inferior rectus, inferior oblique, possibly medial and lateral rectus muscles) and subsequent diplopia, due to lesions to nerve fibres that enter the muscles;

- haemorrhage due to injury to the infraorbital artery or infra-orbital branches of the ophthalmic artery;

- enophthalmos, if the entire orbital floor is resected.

\section{Transnasal (Figures 3 and 4)}

The endoscopic transnasal technique starts performing an uncinectomy and a maxillary antrostomy in order to obtain a good exposure of the posterior maxillary wall and orbital floor, and also to avoid obstruction due to inferior dislocation of orbital fat. Then a complete sphenoid-ethmoidectomy exposes the medial orbital wall from the sphenoid sinus down to the crista ethmoidalis and superiorly to the skull base. In some cases, it is possible to realize the resection of the middle turbinate for better visualization with subsequent cauterization of its postero-lateral remnant to avoid postoperative bleeding. The second step of the procedure is the removal of the bone from the inferior and medial orbital wall.

The lamina papyracea is then fractured with a blind dissector and elevated away from periorbita. Bone is thicker in the region of the orbital apex in the proximity of the annulus of Zinn, through which the optic nerve passes and 


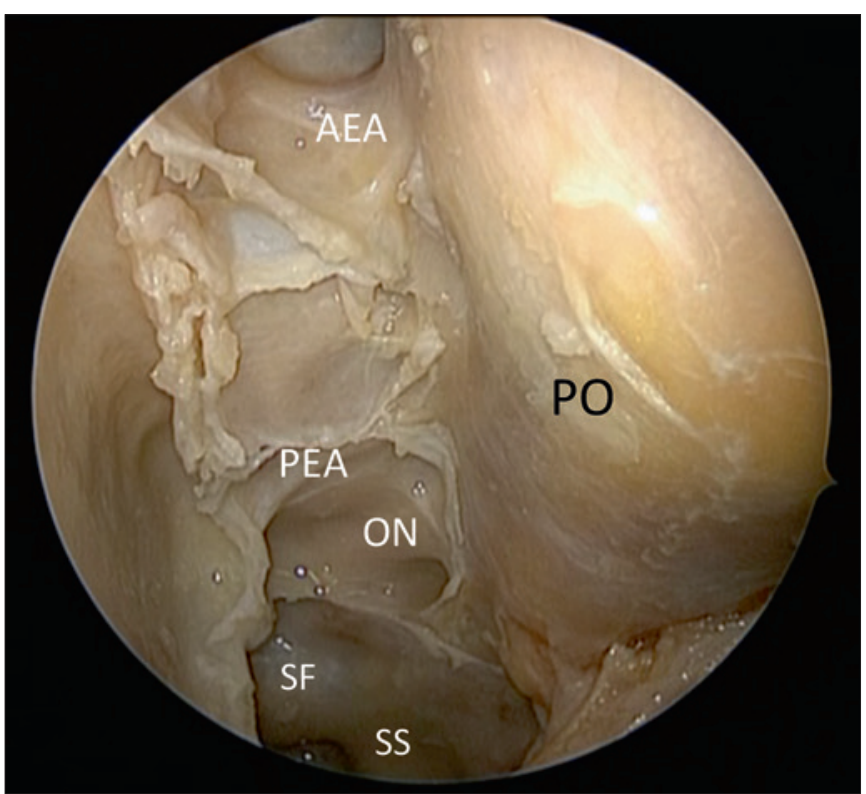

Figure 3. Anatomic dissection showing the periorbit (P0) after complete spheno-ethmoidectomy with the exposure of the Skull base from the I fovea ethmoidalis, anterior ethmoidal artery (AEA), Posterior ethmoidal artery (PEA); to the sphenoid sinus and the following structures: Optic nerve (ON), Interoptic carotid recess and sellar floor Sphenoid Sinus (SS).

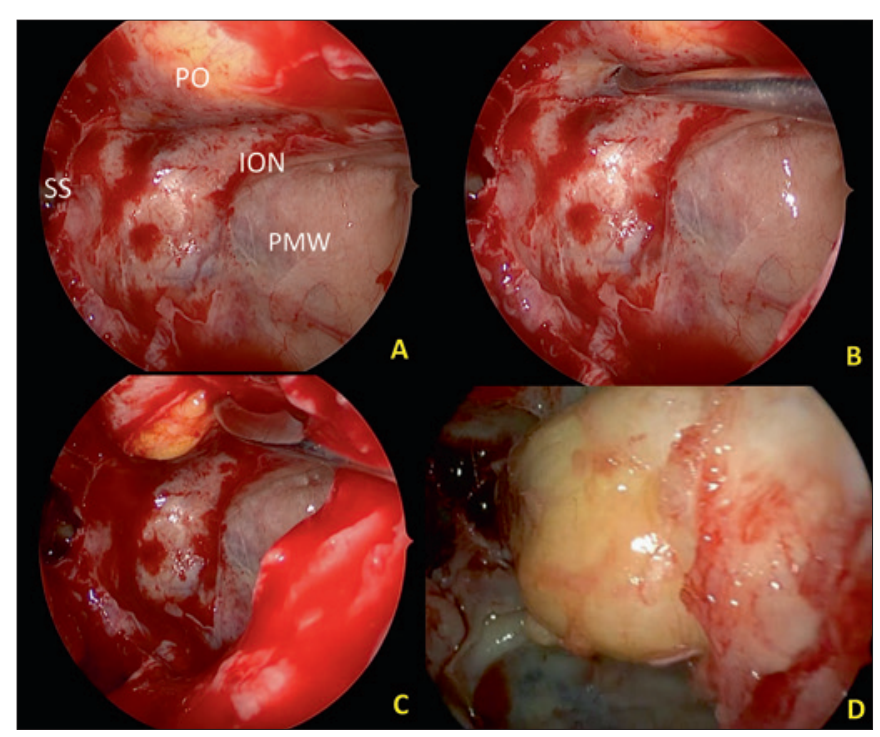

Figure 4. (A-D) Intraoperative view of left orbital decompression with the exposure of the sphenoid sinus (SS), Posterior maxillary wall (PMW), infraorbital nerve (ION), with incision of the inferior periorbit and the final fat ernjation.

where four extraocular muscles originate. Then, the periorbita can be elevated off the bony floor of the medial orbit. Only the portion of the floor that is medial to the infraorbital nerve is removed, preserving its canal as the lateral limit of dissection. Moreover, the preservation of a bony inferior-medial strut may reduce postoperative diplopia and help in improving proptosis ${ }^{35}$. The next step is the incision of the periorbita to enable extraconal orbital fat herniation into the ethmoid and maxillary cavities, avoiding lesions to the orbital contents, in particular of the medial rectus muscle. In order to decrease the risk of postoperative diplopia, it could be preserved the periorbital sling that covers the medial rectus muscle, as described by Metson and Samaha ${ }^{6}$.

\section{Complications}

The more common complications of this kind of surgery include epistaxis, nasal adhesions, sinusitis, worsening of pre-existing diplopia or new-onset diplopia; pre-operative diplopia frequently does not resolve with surgery. Rare complications are represented by injury to the optic nerve and ophthalmic artery; otherwise, cerebrospinal fluid leaks rarely occur ${ }^{36}$.

\section{Bony removal, periosteum opening and fat resection}

The techniques and extent of bony removal widely differ in the literature. Currently, for the floor the lateral extent removal has been limited to the space medial of the infraorbital nerve ${ }^{2}$. Anteriorly, some suggest leaving $10 \mathrm{~mm}$ of bone under the globe to prevent hypoglobus ${ }^{37}$. The limits of medial wall removal differ depending on the surgeon and the clinical features. Anteriorly, the maximal extent is classically thought to be the posterior lacrimal crest ${ }^{2}$. Posteriorly, most descriptions involve dissection to the anterior wall of the sphenoid sinus; however, dissection can extend as far as the optic canal ${ }^{2}$. Many endonasal approaches describe canal decompression as part of the management for DON ${ }^{38}$.

Superiorly, most authors describe dissection to the frontoethmoidal suture. At this level, it is critical to be aware of the skull base anatomy, as inadvertent entry into the cranial cavity through the fovea ethmoidalis has been reported ${ }^{39}$. Inferiorly, the inferior-medial orbital strut separates the medial and inferior walls and provides structure to the bony orbital cone. Authors have argued that removing this strut is important to allow for complete prolapse of the orbital tissue and maximal decompression. Others have suggested that leaving the strut (or part of it) intact is vital to avoid hypoglobus and important strabismus postoperatively ${ }^{31,35}$. The orbital periostium is unelastic and will minimize prolapse of orbital fat in periorbital spaces. For this reason, some suggest opening periostium completely after the bony decompression.

Other authors have suggested cross-hatching or linear incisions ${ }^{31}$.

Extensive opening of the periosteum has been associated with greater rates of postoperative strabismus ${ }^{37}$.

Medially, endoscopic surgeons have described the impor- 
tance of leaving a strip of periosteum overlying the medial rectus and the inferior rectus to reduce the rate of eye inferior prolapse and strabismus ${ }^{6}$.

The infraorbital nerve should be spared to avoid permanent anaesthesia dissecting the orbital floor only medial to the nerve or leaving a bony canal and dissecting on either side ${ }^{31}$.

\section{Lateral wall decompression}

Lateral orbitotomy is an external approach first described by Krönlein in 1888 and since then has undergone some modifications. The original approach involved a curvilinear incision running towards the lateral canthus from the hairline ${ }^{31}$. Stallard and Wright modified the incision with a more acceptable postoperative scar running through the eyebrow ${ }^{40}$. Berke in 1953 proposed a canthal splitting lateral incision ${ }^{41}$, while the first coronal flap to access lateral orbit was described in 1982 by Bonavolonta. Today, the most used approach is the lateral eyelid creased incision that provides excellent access and hides well in the eyelid crease $^{42}$.

The skin incision could be performed in the area of the lateral orbital rim, with possibility of injury to the ramus frontalis and ramus ocularis of the facial nerve, or in alternative, a pterional incision into the hairline could be realized without a cosmetic problem.

With a pterional incision, a scalp flap is formed and prepared until the lateral orbital rim is exposed, preserving the lateral palpebral ligament; temporalis muscle that overlies the lateral orbital wall is incised and bluntly pushed away. Microplates are needed for the reconstruction of the lateral orbital rim. With a saw, the bone at the lateral orbital rim is now separated. This is followed by the resection of the lateral orbital wall including parts of the zygomatic bone up to the greater wing of the sphenoid bone in the region of the inferior orbital fissure.

For the reconstruction of the lateral orbital wall, the temporarily separated bone is repositioned and fixed in place by microplates and the temporalis muscle is moved back and fixed. It could be necessary to insert drainage before closure layer by layer of the scalp.

\section{Complications}

- blunt shape of the lateral canthus due to detachment of the lateral palpebral ligament from the orbital rim;

- impairment of eye globe motility and diplopia because of injury to the lateral rectus and the inferior rectus muscles;

- anisocoria due to injury of the ciliary ganglion (laterally to optic nerve), during very extensive medial preparation;

- disorder of the mimetic musculature due to injury to the ramus frontalis or the ramus orbitalis of the facial nerve;
- sinking of soft tissue above the zygomatic arch because of incomplete repositioning of the temporalis muscle.

\section{Optic nerve decompression}

Many studies have reported the efficacy of medial wall decompression in optic compressive neuropathy. Transcaruncular, transorbital, transantral and endonasal approaches seem similar in the rate of DON improvement reported, range 75$90 \%{ }^{31}$. The periosteum was described not incised, incised in the anteroposterior direction, radially incised. Despite the clinical efficacy of the medial wall optic nerve decompression, a few studies focus on pressure orbital changes ${ }^{43}$.

\section{Discussion}

Most of the literature about orbital decompression consists of retrospective, cohort or case series studies. These papers provide useful descriptive information, but clarification is required to show the effectiveness of each operation related to different indications.

Orbital decompression is achieved by removing bony walls, orbital fat or both. It is an established procedure to correct exophthalmos for visual improvement in patients with optic neuropathy, corneal involvement and for the rehabilitation of patients with marked anterior positioning of the eyes. Several approaches are described with contradicting results, and the comparison of different surgical techniques was biased by inclusion of patients at a different stage of disease (active or inactive), different surgical indications (dysthyroid neuropathy or disfiguring proptosis) and assessment of outcomes (such as a different system for ocular motility evaluation).

The few Randomized Control Trials (RCTs) do not provide robust evidence to support recommendations for clinical practice. There is evidence only from available uncontrolled studies that the removal of the medial and lateral wall (so-called balanced decompression) with or without fat removal could be the most effective surgical technique, related to few complications ${ }^{44}$.

The removal of the inferior wall through the antrum and transnasal removal of the medial wall had similar effects in reducing exophthalmos, but the second approach had a lower rate of complications, such as diplopia and infraorbital nerve damage ${ }^{45}$.

The timing of surgical decompression is another debated issue and must be related to the failure of medical therapy. One of the few RCTs showed how intravenous corticosteroids achieve better visual recovery than surgical orbital decompression (56 vs 17\%) ${ }^{46}$. Adverse outcomes were reported more frequently in the steroids group, i.e. weight gain and a Cushing-like syndrome, hypertension and tran- 
sient diabetes; while side effects of surgery consisted of transient numbness of the facial skin in 4/14 participants or decrease in extraocular muscle motility. The beneficial effect of I.V. steroids on visual rehabilitation would appear to overcome the increased number of transient side effects in active TED with optic neuropathy.

In case of urgent orbital decompression, the main outcome is obviously represented by visual acuity: different studies have demonstrated high success rates with improvements in more than $82 \%$ of patients ${ }^{28,33}$.

Medial and inferior-medial wall decompression is advisable in patients with severe posterior optic neuropathy, caused by apical crowding of the enlarged muscles, in particular of medial rectus.

For nonurgent orbital decompression, proptosis is the main outcome, orbital fat removal alone has been shown to reduce proptosis up to $4.7 \mathrm{~mm}$, while decompression of the medial, inferior, and/or lateral walls could reduce proptosis up to $7.4 \mathrm{~mm}^{28,33}$.

Lateral decompression allows for exophthalmos reduction causing less strabismus, especially with the incision of fascia temporalis. The literature suggests that three-wall decompression is chosen for high degrees of proptosis while two-wall for patients with less exophthalmos; fat removal in addition to bone removal could increase the effectiveness of the procedures ${ }^{44}$.

The aim of orbital decompression surgery is not to create the biggest space with disruption of periorbital structures for maximal decompression, but to realize adequate decompression for relief of optic neuropathy or keratopathy caused by severe proptosis ${ }^{47}$. Moreover, cosmesis, was one of the most common indications for surgery and represented an important quality of life issue for patients ${ }^{48}$.

Several studies suggest that three-wall decompression achieves the greatest reduction in proptosis but that complications are more frequent; for this reason, more conservative approach, such as balanced medial and lateral wall or endoscopic inferior-medial decompression may be preferable choices. The accuracy of measuring proptosis was also questioned. Although postoperative Hertel measurements were widely reported, they were inaccurate in particular when lateral canthotomy is performed, as these were made with a Hertel exophthalmometer using altered reference points, which may result in overestimation of improvement in proptosis ${ }^{47}$.

Interestingly, diplopia can be considered both an outcome and a complication. In every kind of approach, new-onset diplopia could be present at different rates ${ }^{33}$.

Many theories have been proposed to understand this phenomenon, for example, removal of the posterior medial wall, removal of the inferomedial strut, and the displace- ment of the extraocular muscle paths, but no one of these theories has been commonly accepted ${ }^{49}$. It has been suggested that preservation of inferomedial strut and a balanced orbital decompression causes less diplopia and some studies show new onset or worsening of diplopia ranges from 10 to $20 \%{ }^{50-52}$.

Although, some endoscopic surgeons described lower rates of strabismus with modifications to the periosteal opening medially. Additionally, higher rates of over $30 \%$ have been reported for balanced decompression. These rates could be technique dependant, both on the side of balanced decompression and medial decompression alone ${ }^{31}$.

Finally, the comparison of induced diplopia rates after different orbital approaches is difficult to perform because of many factors: type of surgical indications, different measurements, the timing of outcome assessment, different criteria to define the condition.

In the study of Mourits et al. ${ }^{49}$, authors used two tools to assess diplopia: ophthalmologist and orthoptist and determined clinically whether or not there was diplopia in any direction of gaze, while patients self-assessed their diplopia using the Gorman score. Using these criteria seemed to be a tendency for the swinging eyelid approaches to be associated with less induced diplopia. In the group of three-wall swinging eyelid decompression, the incidence of diplopia decreased, and the Gorman score improved. In some studies, the subjective response to treatment was measured using Terwee's GO-QOL, a validated disease-specific questionnaire to assess changes in visual function and changes in appearance ${ }^{53}$.

Various attempts have been made in the literature to study radiographic-based and QOL-based outcomes after orbital decompression, in addition to the evaluation of clinical features.

An objective evaluation could be performed by the imaging measurements of radiographic-based outcomes; recent research has been focused on establishing the validity of an algorithm to determine various parameters, such as the measurement of the angle of the orbital apex, diameter of the extraocular muscles, exophthalmos and orbital volume ${ }^{54-56}$.

Unfortunately, the use of radiographic-based outcomes is not assessed, and its specific role in outcome evaluation needs to be determined by further studies aimed to standardize analyzed parameters.

Probably, in the last years, the most important concept about outcome evaluation is the patient's point of view. For this reason, recently, many questionnaires about quality of life have been developed and validated. One of these is represented by Graves Ophthalmopathy Quality of Life (GOQOL) scale that provides vision-related and appearance- 
related scores, which were assessed before, 6 weeks and 6 months after surgery ${ }^{57}$.

Improvements in eyelid retraction and congested orbit did not predict the change in the appearance-related quality of life. As reported in previous studies, the correlation between clinical changes and quality of life outcomes is weak, also supporting the notion that subjective appraisals of appearance will predict psychological well-being better than clinical measures of severity. For example, patients with strabismus evaluated appearance as more important than other clinical factors ${ }^{57}$.

A recent study has examined the impact of orbital decompression surgery on sinonasal-specific QOL evaluated by SNOT-22 administered preoperatively and one year after surgery, that showed a statistically significant improvement in sinonasal-specific QOL, in particular, improvements have been observed in the psychological domains of the test, confirming a preserved sino-nasal function even after fat prolapse into nasal cavities ${ }^{58}$.

\section{Conclusions and key notes}

TED is the most common indication for orbital decompression in case of failure of medical therapies. The urgent surgical indications are represented by optic neuropathy and severe corneal exposure, while non-urgent surgical indications include diplopia, proptosis, orbital and retrobulbar pain, and ocular hypertension. In the case of optic neuropathy, bony removal in the region of the orbital apex is mandatory, reducing pressure on the optic nerve and leading to improvement in vision in patients with visual loss.

The main clinical outcomes include visual acuity, proptosis, and new-onset diplopia.

Recent studies focused on the development of imaging assessment in order to objectively evaluate the surgical results. QoL questionnaires are gaining increasing importance, based on patients' point of view.

The goal of orbital decompression is the reduction of proptosis, but additional ophthalmological procedures are needed to normal eye function and cosmesis. Strabismus surgery to address diplopia and lowering the position of the upper eyelid represent some of the additional steps for the final rehabilitation of GO.

A balanced decompression (combined external and endoscopic or only external approach) or pure endoscopic approach with the preservation of the anterior inferomedial orbital strut represents the gold standard to reduce the incidence of new-onset diplopia, but RCTs are required to confirm these data. Moreover, the orbital sling technique, obtained by the preservation of a strip of the periorbita overlying the medial rectus muscle is an additional technical trick to reduce diplopia.

\section{References}

Rao R, MacIntosh PW, Yoon MK, et al. Current trends in the management of thyroid eye disease. Curr Opin Ophthalmol 2015;26:484-490. https://doi.org/10.1097/ICU.0000000000000203

2 Kennedy DW, Goodstein ML, Miller NR, et al. Endoscopic transnasal orbital decompression. Arch Otolaryngol - Head Neck Surg 1990;116:275-282. https://doi.org/10.1001/archotol.1990.01870030039006

3 Yao WC, Sedaghat AR, Yadav P, et al. Orbital decompression in the endoscopic age: the modified inferomedial orbital strut. Arch Otolaryngol - Head Neck Surg 2016;154:963-969. https://doi. org/10.1177/0194599816630722

4 Wehrmann D, Antisdel JL. An update on endoscopic orbital decompression. Curr Opin Otolaryngol Head Neck Surg 2016;25:73-78. https://doi.org/10.1097/MOO.0000000000000326

5 Goldberg RA, Shorr N, Cohen MS. The medical orbital strut in the prevention of postdecompression dystopia in dysthyroid ophthalmopathy. Ophthal Plastic Reconstruct Surg 1992;8:32-34. https://doi. org/10.1097/00002341-199203000-00005

6 Metson R, Samaha M. Reduction of diplopia following endoscopic orbital decompression: the orbital sling technique. Laryngoscope 2002;112:17531757. https://doi.org/10.1097/00005537-200210000-00008

7 Bartalena L, Burch HB, Burman KD, et al. A 2013 European survey of clinical practice patterns in the management of Graves' disease. Clin Endocrinol (Oxf) 2016;84:115-120. https://doi.org/10.1111/ cen. 12688

8 Perros P, Hegedüs L, Bartalena L, et al. Graves' orbitopathy as a rare disease in Europe: a European Group on Graves' Orbitopathy (EUGOGO) position statement. Orphanet J Rare Dis 2017;12:72. https:// doi.org/10.1186/s13023-017-0625-1

9 Bartalena L. Graves' orbitopathy: imperfect treatments for a rare disease. Eur Thyroid J 2013;2:259-269. https://doi. org/10.1159/000356042

10 Perros P, Žarković M, Azzolini C, et al. PREGO (presentation of Graves' orbitopathy) study: changes in referral patterns to European Group On Graves' Orbitopathy (EUGOGO) centres over the period from 2000 to 2012. Br J Ophthalmol 2015;99:1531-1535. https://doi. org/10.1136/bjophthalmol-2015-306733

11 Marcocci C, Kahaly GJ, Krassas GE, et al. European Group on Graves' Orbitopathy. Selenium and the course of mild Graves' orbitopathy. N Engl J Med 2011;19;364:1920-1931 https://doi.org/10.1056/NEJMoa1012985

12 Grisolia ABD, Couso RC, Matayoshi S, et al. Non-surgical treatment for eyelid retraction in thyroid eye disease (TED). Br J Ophthalmol 2017 Aug 9;bjophthalmol-2017-310695. https://doi.org/10.1136/ bjophthalmol-2017-310695

13 Bartalena L, Baldeschi L, Boboridis K, et al. European Group on Graves' orbitopathy (EUGOGO). The 2016 European Thyroid Association/European Group on Graves' orbitopathy Guidelines for the Management of Graves' orbitopathy. Eur Thyroid J 2016;5:9-26. https://doi.org/10.1159/000443828

14 Marcocci C, Bartalena L, Tanda ML, et al. Comparison of the effectiveness and tolerability of intravenous or oral glucocorticoids associated with orbital radiotherapy in the management of severe Graves' ophthalmopathy: results of a prospective, single-blind, randomized study. J Clin Endocrinol Metabol 2001;86:3562-3567. https://doi. org/10.1210/jcem.86.8.7737

15 Tanda ML, Bartalena L. Efficacy and safety of orbital radiotherapy 
for graves' orbitopathy. J Clin Endocrinol Metab 2012;97:3857-3865. https://doi.org/10.1210/jc.2012-2758

16 Marquez SD, Lum BL, McDougall IR, et al. Long-term results of irradiation for patients with Graves' ophthalmopathy. Int J Radiat Oncol Biol Phys 2001;51:766-774. https://doi.org/10.1016/s03603016(01)01699-6

17 Wakelkamp IM, Tan H, Saeed P, et al. Orbital irradiation for Graves' ophthalmopathy: is it safe? A long-term follow-up study. Ophthalmology 2004;111:1557-1562. https://doi.org/10.1016/j.ophtha.2003.12.054

18 Mazumder AG, Patial V, Singh D. Mycophenolate mofetil contributes to downregulation of the hippocampal interleukin type 2 and $1 \beta$ mediated $\mathrm{PI} 3 \mathrm{~K} / \mathrm{AKT} / \mathrm{mTOR}$ pathway hyperactivation and attenuates neurobehavioral comorbidities in a rat model of temporal lobe epilepsy. Brain Behav Immun 2019;75:84-93. https://doi.org/10.1016/j. bbi.2018.09.020

19 Kahaly GJ, Riedl M, König J, et al. European Group on Graves' orbitopathy (EUGOGO). Mycophenolate plus methylprednisolone versus methylprednisolone alone in active, moderate-to-severe Graves' orbitopathy (MINGO): a randomised, observer-masked, multicentre trial. Lancet Diabetes Endocrinol 2018;6:287-298. https://doi.org/10.1016/ S2213-8587(18)30020-2

20 Sipkova Z, Insull EA, David J, et al. Early use of steroid-sparing agents in the inactivation of moderate-to-severe active thyroid eye disease: a step-down approach. Clin Endocrinol (Oxf) 2018;89:834839. https://doi.org/10.1111/cen.13834

${ }^{21}$ Pérez-Moreiras JV, Alvarez-López A, Gómez EC. Treatment of active corticosteroid-resistant graves' orbitopathy. Ophthalmic Plast Reconstr Surg 2014;30:162-167. https://doi.org/10.1097/ IOP.0000000000000037

22 Perez-Moreiras JV, Gomez-Reino JJ, Maneiro JR, et al. Tocilizumab in Graves orbitopathy Study Group. Efficacy of tocilizumab in patients with moderate-to-severe corticosteroid-resistant graves orbitopathy: a randomized clinical trial. Am J Ophthalmol 2018;195:181190. https://doi.org/10.1016/j.ajo.2018.07.038

23 Yamamoto K, Goto H, Hirao K, et al. Longterm safety of tocilizumab: results from 3 years of follow-up postmarketing surveillance of 5573 patients with rheumatoid arthritis in Japan. J Rheumatol 2015;42:1368-1375. https://doi.org/10.3899/jrheum.141210

24 Salvi M, Vannucchi G, Currò N, et al. Efficacy of B-cell targeted therapy with rituximab in patients with active moderate to severe Graves' orbitopathy: a randomized controlled study. J Clin Endocrinol Metab 2015;100:422-431. https://doi.org/10.1210/jc.2014-3014

25 Stan MN, Garrity JA, Carranza Leon BG, et al. Randomized controlled trial of rituximab in patients with Graves' orbitopathy. J Clin Endocrinol Metab 2015;100:432-441. https://doi.org/10.1210/ jc.2014-2572

26 Pletcher SD, Sindwani R, Metson R. Endoscopic orbital and optic nerve decompression. Otolaryngol Clini North Am 2006;39:943-958. https://doi.org/ 10.1016/j.otc.2006.06.003

27 Bartalena L, Baldeschi L, Dickinson A, et al. European Group on Graves' Orbitopathy (EUGOGO). Consensus statement of the European Group on Graves' orbitopathy (EUGOGO) on management of GO. Eur J Endocrinol 2008;158:273-285. https://doi.org/10.1530/ EJE-07-0666

28 Braun TL, Bhadkamkar MA, Jubbal KT, et al. Orbital decompression for thyroid eye disease. Semin Plastic Surg 2017;31:40-45. https:// doi.org/10.1055/s-0037-1598192

29 Saeed P, Tavakoli Rad S, Bisschop P. Dysthyroid optic neuropathy. Ophthal Plastic Reconstruct Surg 2018;34:S60-S67. https://doi.org/ 10.1097/IOP.0000000000001146

30 Rootman DB, Golan S, Pavlovich P, et al. Postoperative changes in strabismus, ductions, exophthalmometry, and eyelid retrac- tion after orbital decompression for thyroid orbitopathy. Ophthalmic Plast Reconstr Surg 2017;33:289-293. https://doi.org/10.1097/ IOP.0000000000000758

31 Rootman DB, Orbital decompression for Thyroid Eye Disease.Survey Ophthalmol 2018;63:86-104. https://doi.org/ 10.1016/j.survophthal.2017.03.007

32 Ben Simon GJ, Mansury AM, Schwarcz RM, et al. Simultaneous orbital decompression and correction of upper eyelid retraction versus staged procedures in thyroid-related orbitopathy. Ophthalmology 2005;112:923-932. https://doi.org/10.1016/j.ophtha.2004.12.02833

33 Kingdom TT, Davies BW, Durairaj VD. Orbital decompression for the management of thyroid eye disease: an analysis of outcomes and complications. Laryngoscope 2015;125:2034-2040. https://doi. org/10.1002/lary. 25320

34 Ogura JH, Walsh TE. The transantral orbital decompression operation for 1506 progressive exophthalmos. Laryngoscope 1962;72:10781097. https://doi.org/10.1288/00005537-196208000-00009

35 Finn AP, Bleier B, Cestari DM, et al. A retrospective review of orbital decompression for thyroid orbitopathy with endoscopic preservation of the inferomedial orbital bone strut. Ophthalmic Plastic Reconstruct Surg 2017;33:334-339. https://doi.org/10.1097/ IOP.0000000000000782

36 Sellari-Franceschini S, Dallan I, Bajraktari A, et al. Surgical complications in orbital decompression for Graves' orbitopathy. Acta Otorhinolaryngol Ital 201636:265-274. https://doi.org/10.14639/0392100X-1082

37 Mainville NP, Jordan DR. Effect of orbital decompression on diplopia in thyroid-related orbitopathy. Ophthal Plastic Reconstruct Surg 2014;30:137-140. https://doi.org/ 10.1097/IOP.0000000000000029

38 Schaefer SD, Soliemanzadeh P, Della Rocca D, et al. Endoscopic and transconjunctival orbital decompression for thyroid-related orbital apex compression. Laryngoscope 2003;113:508-513. https://doi. org/10.1097/00005537-200303000-00021

39 McCormick CD, Bearden WH, Hunts JH, et al. Cerebral vasospasm and ischemia after orbital decompression for graves ophthalmopathy. Ophthal Plastic Reconstruct Surg 2004;20:347-351. https://doi. org/10.1097/01.iop.0000134248.64325.c7

40 Stallard HB. The presidential address. The evolution of lateral orbitotomy. Trans Ophthalmol Soc UK 1973;93:3-17.

41 Berke RN. A modified Kronlein operation. Trans Am Ophthalmol Soc 1953;51:193-231.

42 Sellari-Franceschini S, Lenzi R, Santoro A, et al. Lateral wall orbital decompression in graves' orbitopathy. Int J Oral Maxillofacial Surg 2010;39:16-20. https://doi.org/10.1016/j.ijom.2009.10.011

43 McCord CD, Putnam JR, Ugland DN. Pressure-volume orbital measurement comparing decompression approaches. Ophthal Plastic Reconstruct Surg 1985;1:55-63. https://doi.org/10.1097/00002341198501000-00009

44 Boboridis KG, Bunce C. Surgical orbital decompression for thyroid eye disease. Cochrane Database System Rev 2011;12:CD007630. https://doi.org/10.1002/14651858.CD007630.pub2

45 Pliego-Maldonado A, Miranda-Ruiz R, Vargas-Aguayo A, et al. Orbit decompression surgery in patients with exophthalmos caused by Graves-Basedow disease [Cirugía descompresiva de la órbita en pacientes con exoftalmos por enfermedad de Graves-Basedow]. Gaceta Médica de México 2000;136:11-5.

46 Wakelkamp IM, Baldeschi L, Saeed P, et al. Surgical or medical decompression as a first-line treatment of optic neuropathy in Graves' ophthalmopathy? A randomized controlled trial. Clin Endocrinol 2005;63:323-328. https://doi.org/10.1111/j.13652265.2005.02345.x

47 Leong SC, Karkos PD, MacEwen CJ, et al. A systematic review of 
outcomes following surgical decompression for dysthyroid orbitopathy. Laryngoscope 2009;119:1106-1115. https://doi.org/10.1002/ lary. 20213

48 Tehrani M, Krummenauer F, Mann WJ, et al. Disease-specific assessment of quality of life after decompression surgery for Graves' ophthalmopathy. Eur J Ophthalmol 2004;14:193-199. https://doi. org/10.5301/EJO.2008.2576

49 Mourits MP, Bijl H, Altea MA, et al. (EUGOGO) outcome of orbital decompression for disfiguring proptosis in patients with Graves' orbitopathy using various surgical procedures. $\mathrm{Br} \mathrm{J}$ Ophthalmol 2009;93:1518-1523. https://doi.org/10.1136/bjo.2008.149302

50 Kacker A, Kazim M, Murphy M, et al. "Balanced" orbital decompression for severe Graves' orbitopathy: technique with treatment algorithm. Otolaryngol Head Neck Surg 2003;182:228-235. https://doi. org/10.1067/mhn.2003.61

51 Sellari-Franceschini S, Berrettini S, Santoro A, et al. Orbital decompression in Graves' ophthalmopathy by medial and lateral wall decompression. Otolaryngol Head Neck Surg 2005;133:185-189. https://doi.org/10.1016/j.otohns.2005.02.006

52 Sellari-Franceschini S, Berrettini S, Forli F, et al. Orbital decompression in Grave's disease: comparison of techniques. Acta Otorhinolaryngol Ital 1999;19:307-314.

53 Terwee CB, Gerding MN, Dekker FW, et al. Development of a disease specific quality of life questionnaire for patients with Graves' ophthalmopathy: the GO-QOL. Br J Ophthalmol 1998;82:773-779. https://doi.org/10.1136/bjo.82.7.773

54 Kang EM, Yoon JS. Clinical and radiological characteristics of Graves' orbitopathy patients showing spontaneous decompression. J Cranio-Maxillo-Facial Surg 2015;43:48-52. https://doi.org/10.1016/j. jcms.2014.10.008

55 Thapa S, Gupta AK, Gupta A, et al. Proptosis reduction by clinical vs radiological modalities and medial vs inferomedial approaches: comparison following endoscopic transnasal orbital decompression in patients with dysthyroid orbitopathy. JAMA Otolaryngology Head Neck Surg 2015;141:329-334. https://doi.org/10.1001/jamaoto. 2014.3659

56 Schiff BA, McMullen CP, Farinhas J, et al. Use of computed tomography to assess volume change after endoscopic orbital decompression for Graves' ophthalmopathy. Am J Otolaryngol 2015;36:729-735. https://doi.org/10.1016/j.amjoto.2015.06.005

57 Wickwar S, McBain H, Ezra DG, et al. The psychosocial and clinical outcomes of orbital decompression surgery for thyroid eye disease and predictors of change in quality of life. Ophthalmology 2015;122:25682576.e1. https://doi.org/10.1016/j.ophtha.2015.08.030

58 Mueller SK, Miyake MM, Lefebvre DR, et al. Long-term impact of endoscopic orbital decompression on sinonasal-specific quality of life. Laryngoscope 2018;128:785-788. https://doi.org/10.1002/ lary.26812 